
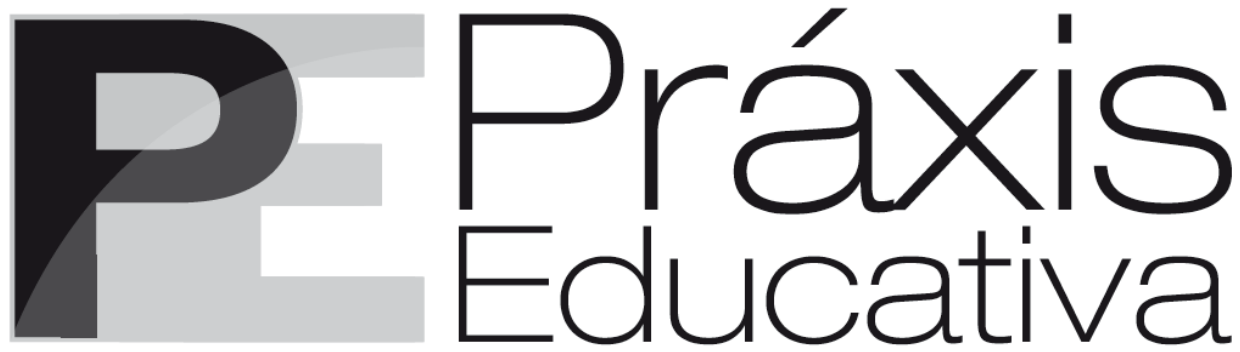

ISSN 1809-4031

elSSN 1809-4309

https://doi.org/10.5212/PraxEduc.v.16.16641.053

\title{
A força da palavra dos vulnerabilizados pela desigualdade social: Paulo Freire e comunidades ribeirinhas no Marajó
}

The strength of the word of those vulnerable by social inequality: Paulo Freire and riverside communities in Marajó

\section{La fuerza de la palabra de los vulnerabilizados por la desigualdad social: Paulo Freire y comunidades ribereñas de Marajó}

Eunápio Dutra do Carmo*

iD https://orcid.org/0000-0002-8186-8789

Éder Dutra do Carmo ${ }^{* *}$

(iD) https://orcid.org/0000-0003-4437-4760

Resumo: Este artigo, ambientado nas contribuições de Paulo Freire, analisa as experiências coletivas de comunidades ribeirinhas marajoaras em busca da garantia de direitos. Parte-se da ideia de educação como ato político (FREIRE, 1987, 1992, 1996) e da discussão crítica sobre o modelo de desenvolvimento capitalista-colonial (CASTRO, 2010) para pensar e agir diante do atual quadro de vulnerabilidade social. Metodologicamente, adotou-se a linha de reflexão interdisciplinar dos campos da Educação Popular e da Sociologia que caracteriza a abordagem crítica do artigo. As fontes primárias foram oriundas da valorização da palavra em rodas de conversa, das oficinas sobre organização social e da afirmação da cultura em atividades comunitárias. Os resultados apontam para iniciativas de formação de associação de moradores, qualificação para atividades de geração de renda e o reconhecimento do valor das comunidades ribeirinhas como portadoras de histórias, de potências e de direitos socioterritoriais.

Palavras-chave: Comunidades ribeirinhas. Direitos. Organização social.

Abstract: This article, based on Paulo Freire's contributions, analyzes the collective experiences of riverside communities of the Marajó Archipelago, Pará, Brazil, in search of guaranteeing rights. It starts with the idea

\footnotetext{
* Professor da Faculdade de Serviço Social da Universidade Federal do Pará (UFPA) - campus Universitário do MarajóBreves. Doutor em Educação pela Pontifícia Universidade Católica do Rio de Janeiro (PUC-Rio). Coordena o Programa Redes de Comunidades Ribeirinhas (PRCR), é membro do Grupo de Pesquisa Estado, Território, Trabalho e Mercados Globalizados na Amazônia e integrante da Rede de Pesquisa sobre Pedagogias Decoloniais na Amazônia. E-mail: <eunapiodocarmo@gmail.com>.

** Professor do Ensino Médio (Centro de Serviços Educacionais do Pará). Educador Popular. Integrante do Movimento Negro da Periferia de Belém. Graduando em História (Universidade da Amazônia). E-mail: <edermarley@yahoo.com.br>.
} 
A força da palavra dos vulnerabilizados pela desigualdade social: Paulo Freire e comunidades ribeirinhas...

of education as a political act (FREIRE, 1987, 1992, 1996) and the critical discussion about the capitalistcolonial development model (CASTRO, 2010) to think and act in the face of the current social vulnerability. Methodologically, the line of interdisciplinary reflection in the fields of Popular Education and Sociology, which characterizes the critical approach of the article, was adopted. The primary sources came from the valorization of the word in conversation circles, from workshops on social organization and from the affirmation of culture in community activities. The results point to initiatives for the formation of residents' associations, qualification for income generation activities and the recognition of the value of riverside communities as holders of histories, potencies and socio-territorial rights.

Keywords: Riverside communities. Rights. Social organization.

Resumen: Este artículo, ambientado en las contribuciones de Paulo Freire, analiza las experiencias colectivas de las comunidades ribereñas de Marajó, Pará, Brasil, en busca de la garantía de derechos. Se parte de la idea de la educación como acto político (FREIRE, 1987; 1992,1996) y de la discusión crítica sobre el modelo de desarrollo capitalista-colonial (CASTRO, 2010) para pensar y actuar falante del cuadro actual de vulnerabilidad social. Metodológicamente, se adoptó la línea de reflexión interdisciplinar de los campos de la Educación Popular y de la Sociología que caracteriza el enfoque crítico del artículo. Las fuentes primarias fueron oriundas de la valorización de la palabra en los círculos de conversación, de los talleres sobre organización social y de la afirmación de la cultura en las actividades comunitarias. Los resultados apuntan a iniciativas para la formación de asociaciones de vecinos, la calificación para actividades de generación de ingresos y el reconocimiento del valor de las comunidades ribereñas como portadoras de historias, potencias y de derechos socio-territoriales.

Palabras clave: Comunidades ribereñas. Derechos. Organización social.

\section{Introdução}

A palavra em Paulo Freire é afirmação da existência. Nela estão embutidas o afeto e a transformação. Essa conexão afirma a centralidade da palavra e a sua ressignificação. A palavra é atitude, direito, escuta e diálogo. Enfim, palavra é estar vivo em plenitude (FREIRE, 1987, 1992, 1996, 2000). Foi uma palavra dita por uma ribeirinha no barracão comunitário da Vila Intel em Breves, capital do arquipélago do Marajó", que inspirou as reflexões deste artigo: "Por que sempre esquecem de nós? Por quê?". Nas comunidades ribeirinhas, dar uma palavra significa dar a oportunidade de falar e ser escutado por todos. Essa palavra calou fundo, fez-se silêncio e, depois, gerou muitas outras palavras. Trata-se da invisibilidade das comunidades ribeirinhas do Marajó que vivem, muitas delas, em condições degradantes, reflexo da intensa expansão do sistema capitalista na Amazônia, provocando desastres socioambientais e conflitos territoriais, além da agudização da exclusão social. Assim sendo, o esquecimento é produzido socialmente por uma ideologia hegemônica que valoriza o urbano-industrial com políticas públicas adequadas ao desenvolvimento econômico em detrimento de uma agenda social que assegure a territorialização de políticas sociais para as comunidades ribeirinhas.

Esse atual contexto social instigou os integrantes do Programa Redes de Comunidades Ribeirinhas (PRCR), vinculado à Faculdade de Serviço Social da Universidade Federal do Pará (UFPA) - campus Universitário Marajó-Breves, e orientou todas as ações integradas e intersetoriais junto às comunidades ribeirinhas Vila Intel I, Vila Intel II e Magebras ${ }^{2}$. A partir dessa abordagem

\footnotetext{
${ }^{1} \mathrm{O}$ arquipélago do Marajó, com seu conjunto de 2.500 ilhas, ilhotas e 16 municípios, está na foz do Rio Amazonas e é emblemático na manifestação da pujante sociobiodiversidade da região. De Belém ao Marajó, percorre-se $223 \mathrm{~km}$ para atravessar, via transporte fluvial, as baías de Guajará e do Marajó, bacias com extensões gigantescas devido à proximidade com o Oceano Atlântico, e navega-se por labirintos de rios, furos, igarapés, tornando a navegabilidade dos rios uma cultura (i)material de fator dominante na "[...] estrutura fisiográfica e humana, conferindo um ethos e um ritmo à vida regional" (LOUREIRO, 2015, p. 29).

2 O Programa é atravessado por uma dinâmica interdisciplinar de reflexões e análises epistêmicas diversas, mas é, fundamentalmente, ancorado na troca de saberes das experiências de atores e entidades sociais (comunidades,
}

Práxis Educativa, Ponta Grossa, v. 16, e2116641, p. 1-14, 2021

Disponível em: <https://www.revistas2.uepg.br/index.php/praxiseducativa> 
interdisciplinar e da pesquisa-ação, e das experiências de pesquisa e extensão do autor com comunidades na Amazônia, o artigo propõe-se a analisar as experiências coletivas de comunidades ribeirinhas marajoaras em busca da garantia de direitos.

Com esse recorte, os dados qualitativos foram resultados das relações sociais que se estabelecem nas comunidades Vila Intel I, Vila Intel II e Magebras e entre elas, com seus desdobramentos desenvolvidos a partir das práticas sociais mediante um processo de imersão na comunidade. Além disso, procurou-se estabelecer uma aproximação com os moradores, perfazendo muitas interações, conversas e outras formas de contato que ajudaram na busca de informações e de intervenções na costura educação, cultura e meio ambiente para a compreensão do cenário social. Para tanto, as técnicas utilizadas foram: escuta sensível, grupo focal, reuniões e oficinas nas comunidades, mural das águas, casas de memória. Também importa destacar os valores éticos que asseguram, além da importância da pesquisa, o retorno para as pessoas envolvidas na medida em que são beneficiadas com a visibilidade das causas socioculturais inerentes às investigações. A entrada no campo pressupõe mediação e desenvolvimento de mecanismos de confiança, tanto no sentido do anonimato como na segurança das informações que são refletidas na análise das questões de pesquisa, bem como no compromisso social e na qualidade e no método de repasse das informações às comunidades envolvidas.

Diante dessas considerações, a estrutura do artigo parte da compreensão do processo de dominação da modernidade/colonialidade. Na sequência, serão apresentadas as experiências sociais das comunidades ribeirinhas com base nas reflexões freireanas. Em seguida, serão analisados os principais desafios que tensionam e problematizam as territorialidades em disputa e a ação coletiva das comunidades ribeirinhas. Nas considerações finais, algumas sinalizações de avanços e de agendas futuras serão apresentadas, bem como o aprendizado com as lutas históricas dos povos das florestas e das águas.

\section{A dominação da colonização e as várias formas de opressão}

A grande vulnerabilidade social da região marajoara, amplamente divulgada nas diversas mídias, desafia a sociedade amazônica e, em especial, a gestão pública, as academias e os institutos de pesquisa. Para superar a naturalização e a simplificação desse tema, alguns cuidados são relevantes. Qualquer iniciativa para compreendê-lo exige análises combinadas que envolvam processos históricos e desafios contemporâneos, ambos marcados por uma sociedade predominantemente ribeirinha e agroextrativista integrada, pela via do mercado, ao mundo globalizado. Assim ocorreu com a territorialização da madeira na Amazônia Marajoara ao cumprir a agenda do modelo de desenvolvimento econômico com a expansão produtiva e demográfica, somada à concessão de subsídios favoráveis à exploração predatória de madeira e à apropriação privada do território que, por sua vez, provocou a desestruturação socioambiental do espaço social, afetando comunidades e povos tradicionais.

É nesse contexto de mudanças econômicas e sociais que se localizam as ações de pesquisaextensão, ocupando-se dos debates sobre os resultados do modelo de desenvolvimento imposto à Amazônia, marcado pelo saque (CASTRO, 2012), pelo aprofundamento da injustiça social e pela produção de impactos socioambientais. Assim, a integração efetiva e permanente da região à dinâmica financeira e de mercado, como fornecedora de recursos naturais, de mão de obra em abundância e de subsídios do Estado, está diretamente relacionada aos processos de exclusão social,

universidades, órgãos públicos e organizações sociais) em uma perspectiva intersetorial e transescalar. A proposta central é ampliar a participação social dos membros das comunidades ribeirinhas. O foco é a organização social para a garantia de direitos sociais e a valorização das comunidades ribeirinhas como a grande centralidade.

Práxis Educativa, Ponta Grossa, v. 16, e2116641, p. 1-14, 2021

Disponível em: <https://www.revistas2.uepg.br/index.php/praxiseducativa> 
A força da palavra dos vulnerabilizados pela desigualdade social: Paulo Freire e comunidades ribeirinhas...

mas que se justifica pelos padrões de consumo e estilos de vida da sociedade urbano-industrial incompatíveis com a dinâmica de vida dos povos da floresta e perfeitamente compatível com o paradigma de acumulação capitalista, um padrão histórico desde os processos coloniais de ocupação e domínio da região.

Os processos de vulnerabilização são históricos na região e remontam ao período colonialescravocrata, os quais se intensificaram com o pós-crise do ciclo da madeira na região. Nessa direção, a formação socioeconômica do Arquipélago do Marajó é marcada pelo desenvolvimento desigual que corresponde, historicamente, ao processo de formação socioeconômica da Amazônia. Ambas as reflexões estão apoiadas no processo de expansão do sistema capitalista como modo de produção baseado na propriedade privada e no trabalho assalariado, considerados prioritários diante das vidas humanas e da natureza, tendo como alvo a reprodução ampliada do capital, dos lucros financeiros, voltados ao mercado internacional. A produção da dominação deu-se também com base na colonialidade do poder, do ser e do saber, subjulgando processos culturais, memórias e histórias para prevalecer a hegemonia da modernidade/colonialidade (QUIJANO, 2010). Os avanços das epistemologias do Sul e as contribuições sociopolíticas dos estudos subalternos são vetores importantes na reversão de estruturas históricas de dominação. Nesse sentido, os processos emancipatórios estão no curso da formação humana, confirmada pelas conformações inacabadas da constituição humana (GONÇALVES; BOMFIM, 2021). É na potência política de criticar e denunciar os processos de reprodução da desigualdade social, promovidos pelo sistema-mundo capitalista, e de contribuir para impulsionar movimentos de transgressões epistêmicos e políticosociais que este artigo se ambienta, tendo como objetivo central analisar as tensões e as insurgências das práticas sociais das comunidades ribeirinhas em curso no Marajó na perspectiva da decolonialidade.

Todo esse processo de universalização e mobilidade do capital, somado à ideologia e aos processos da colonialidade, se espacializam em diversas formas e interesses, gerando impactos múltiplos e desorganizando as estruturas sociais pré-existentes. Nas palavras de Brandão (2012, p. 52): "É inconteste que o movimento de acumulação de capital se processa, em sua expressão espacial, de forma mutável, parcial, diversa, irregular e com alta seletividade". No caso da Amazônia e, por conseguinte, do Marajó, a dimensão espacial do desenvolvimento trouxe desterritorialização e reterritorialização dos povos da floresta. A incidência dessa dominação acarretou genocídio social e epistemicídio (SANTOS, 2007), e, além disso, houve desestruturação socioambiental que impactou gerações de comunidades quilombolas, indígenas e ribeirinhas, justificada pelo crescimento econômico via integração ao mercado. Tais implicações são danosas para toda uma geração e ancestralidade. Ainda em Brandão (2012, p. 31), todo esse contexto apontou a "[...] natureza desigual e combinada de desenvolvimento capitalista, envolvendo dominação e irreversibilidade, próprias da polarização".

A precarização do sistema de saúde é uma das opressões desse processo que têm implicações diretas na vida e no bem-estar desses grupos. Observa-se que as estruturas sociais e econômicas acenam para uma vulnerabilidade socioeconômica com desdobramentos para a segurança de saúde e sanitária e revela "[...] uma carência de políticas públicas dirigidas a corrigir a crítica situação dos baixos índices da presença de fossa séptica, rede geral de esgotos, ausência de coleta de lixo e a limitada rede de distribuição de água" (SILVA; AMIN; NUNES, 2015, p. 304). Bôas e Oliveira (2016) fizeram uma revisão da literatura sobre a saúde de comunidades ribeirinhas na região Norte. Os autores apontam que os determinantes sociais de saúde explicam aspectos de "[...] isolamento territorial e acesso limitado aos cuidados, constituindo um grupo com demandas peculiares ao sistema oficial de saúde” (BÔAS; OLIVERIA, 2016, p. 1386).

Práxis Educativa, Ponta Grossa, v. 16, e2116641, p. 1-14, 2021

Disponível em: <https://www.revistas2.uepg.br/index.php/praxiseducativa> 
O fato é que essa região sofre ainda as consequências da expansão do modelo capitalista de extração e de beneficiamento de arroz, borracha e, principalmente, madeira, alterando a dinâmica do ecossistema local (devastação, desmatamento, queimadas, poluição dos rios, desterritorialização de comunidades, insegurança alimentar e ataque à sociobiodiversidade) e afetando diretamente a saúde ambiental da região e, por conseguinte, a saúde humana, que está determinada por múltiplos aspectos complexos e sistêmicos (fatores físico-químicos, biológicos, econômico-sociais e psicológicos). O desenvolvimento desigual é historicamente marcado pela extração de riquezas e pela espacialização de desigualdade social que se reproduz em uma estrutura socioambiental e econômica enraizada no poder local como ingerência do mercado internacional, como aconteceu e acontece com a Amazônia, via grandes grupos e megaempreendimentos extrativistas e de infraestrutura (BRANDÃO, 2012; CASTRO, 2010, 2012).

A saúde às margens dos rios, dos furos, dos igarapés, das várzeas e das florestas densas é marcada pelas contradições entre a força da sociobiodiversidade marajoara e a extrema desigualdade social no cotidiano rico e exuberante. Quando se navega por essa região, avistam-se crianças tomando banho no rio, mulheres lavando roupa, homens pescando, outros passando com canoas de açaí "tirado" das palmeiras das várzeas, barcos com estudantes indo para escolas, "rabetas" (pequenas embarcações) trafegando nas mais diversas trilhas de rios. É nesse cotidiano que a saúde é produzida socialmente. Saúde, portanto, não significa o contrário de doença. Significa qualidade de vida e lugar de felicidade no território. Verifica-se que as condições de vida estão fragilizadas nessa região por entender que o processo de cuidado integral é amplo e envolve processos biopsicossociais territorializados em ambientes e contextos, cujo conhecimento e estudo são fundamentais para a efetiva atenção primária à saúde de populações ribeirinhas, nas quais a palavra, as informações e o conhecimento são fundamentais.

Os processos de saúde-cuidado estão associados às formas de produção de conhecimento sobre si e sobre o mundo. É na maneira como o ribeirinho compreende a sua condição de existência que a saúde se estabelece e o transforma. Para o trabalho e para a intervenção metodológica do programa é vital entender que a variação de mundo implica variação de políticas, de modelos e de práticas em saúde e uma forma de pensar saúde "com" e não "para" as comunidades ribeirinhas, acarretando alteridade, diferenças e conexões com multiplicidade de mundo, de conhecimentos e de formas de conceber. Uma abordagem sempre inclusiva e complementar, sem hierarquia e níveis de importância. A questão da sobrevivência e dos cuidados desses grupos é essencial e extremamente contemporânea, haja vista a crise sanitária provocada pela pandemia de COVID-19 ${ }^{3}$ que assola o mundo.

De fato, uma rede em permanente construção com participação comunitária deve ser estimulada. Percebeu-se que, durante as visitas, para a integralidade das ações em saúde, nessa perspectiva da rede e da participação comunitária, torna-se necessário: buscar entender os territórios como espaços de promoção de saúde por sua relação orgânica com os usuários; estudar as fronteiras de cuidado para alinhar a prática com a efetividade do processo de saúde à realidade encontrada de desestruturação socioambiental e negação das referências culturais; e superar a colonialidade do saber na perspectiva da saúde ribeirinha, assentada nos territórios, e seus saberes gestados nas águas e nas florestas.

\footnotetext{
3 Esse quadro sanitário agudizado revela múltiplas desigualdades (social, econômica e em saúde) e reforça a compreensão de que a crise sanitária, em que Breves foi, em maio de 2020, a cidade mais contaminada no Brasil (G1PARÁ, 2020), potencializou as demais crises já bem conhecidas na região: crise social com aumento da extremapobreza; crise econômica com aumento da informalidade; e crise da saúde com precarização atestada pela baixíssima infraestrutura e pelos serviços.
} 
A força da palavra dos vulnerabilizados pela desigualdade social: Paulo Freire e comunidades ribeirinhas...

Com as comunidades ribeirinhas, é importante perceber a dinâmica homem-rio-floresta como território de existência, trabalho e transporte, adaptado a um estilo de vida em que o tempoespaço são próprios e respeitam as estações dos ecossistemas, onde as casas são de madeira e adaptadas ao sistema de cheia e vazante do rio. Muitas casas estão em condições precárias e o conjunto delas está ligado por pontes construídas para circulação das pessoas. Há o mínimo de saneamento básico e água potável que prejudica o desenvolvimento biofísico das pessoas. As doenças hídricas disseminadas por parasitas são constantes e próprias da região e afetam a população de forma endêmica. Algumas pesquisas apontam grande quantidade de coliformes fecais nos locais de abastecimento de águas das comunidades ribeirinhas nascentes, igarapés e poços. Também não há um destino apropriado do lixo - ele pode ser queimado, usado como adubo ou despejado em lugares abertos, aumentando as contaminações e os problemas de saúde (endemias e epidemias causadas por parasitas). A diarreia é um dos casos endêmicos causados por essa realidade de disseminação de parasitas intestinais. De um modo geral, algumas medidas preventivas podem diminuir os casos, como tratamento da água, higienização dos alimentos e fossas sanitárias adaptáveis.

Em geral, o fechamento de escolas, a insegurança alimentar, o desemprego, a precarização das pontes e a falta de transporte somam-se aos problemas relatados. As palavras das gentes do território das águas e das florestas são carregadas de denúncia e anúncio que dizem respeito aos "efeitos derrame" (GUDYNAS, 2016) do choque vivido pelas comunidades ribeirinhas em decorrência da ofensiva mobilidade do capital na região, gerando problemas permanentes devido aos desastres socioambientais e econômicos. Afinal, quem são os invasores? À que lógica atendem? $\mathrm{O}$ que querem e para que querem? Isso porque as comunidades dos ecossistemas aquáticos conseguiram consolidar saberes, técnicas e tecnologias que valorizam a floresta em pé, a manutenção do equilíbrio dos rios e a preservação da sociobiodiversidade. A esse respeito, Romão e Gadotti (2012) discutem o importante processo de deslocalização das mentes inspirados em Paulo Freire e Amílcar Cabral, considerados autores de práxis.

\section{Comunidades ribeirinhas: de populações negadas a sujeitos políticos}

As comunidades da "beira do rio" da Amazônia têm uma relação orgânica com os ecossistemas. A relação dos ribeirinhos com rios-várzeas-terra-firme implica a existência desses grupos socialmente diferenciados. No entanto, a história desses grupos é marcada pela inviabilidade, pela negação e pelos conflitos, fruto de processos de subjugação aos ciclos capitalistas que vêm se expandindo na Amazônia desde o período colonial e que permanecem até hoje. $\mathrm{O}$ caráter destruidor e opressor do período foi sofisticando-se pelas narrativas oficiais de desenvolvimento local, de sustentabilidade e de crescimento econômico (CASTRO, 2010).

Na Amazônia Marajoara, os ciclos econômicos da borracha, do arroz, do palmito e da madeira foram responsáveis por transformações na paisagem social, econômica e ambiental da região. No contexto de disputas e de conflitos, as comunidades ribeirinhas são consideradas "não gente" na mesma linha da narrativa de vazio demográfico estrategicamente aceito para justificar a posse das terras, a destruição da natureza e das histórias dos povos da floresta (CASTRO, 2012; PORTO-GONÇALVES, 2015). A história social dessas comunidades é, portanto, a história da destruição, da devastação e do aniquilamento, cujo reflexo está na contemporaneidade da precária presença do poder público e da pouca efetivação de políticas públicas. Em outro patamar, a sociobiodiversidade está na matriz de reprodução social da vida das comunidades ribeirinhas. $\mathrm{O}$ conjunto ar, água e terra compõe o território ancestralmente construído em sabedoria, tecnologia e trabalho. O código de existência desses grupos está inscrito no território das águas marajoaras, e toda a sociabilidade afetiva, emocional, cultura e ambiental compõe o mundo ribeirinho. Isso para

Práxis Educativa, Ponta Grossa, v. 16, e2116641, p. 1-14, 2021

Disponível em: <https://www.revistas2.uepg.br/index.php/praxiseducativa> 
dizer que há ciência, inteligência e memória social forjadas nessa longa relação homem-natureza e não na sua divisão. Por essa razão, o desequilíbrio desse espaço social é profundamente um ataque aos modos de vida e corresponde à produção de insegurança e de destruição permanentes.

As famílias mantêm ampla rede de parentesco. São, predominantemente, caboclos, de origem afrodescendente e portuguesa, com forte tradição de relação com o ecossistema. Assim sendo, aprenderam a "lidar com a floresta" e, tradicionalmente, desenvolveram atividades de subsistência nos quintais, na pesca e no roçado. A memória social dos integrantes é, também, a identidade dessas comunidades, pois as experiências foram socioculturalmente construídas. Essa riqueza mítica e cultural compõe as histórias das comunidades ribeirinhas, feitas de muitas outras memórias, e o fio condutor dessas histórias é o rio, como território privilegiado que contém elementos (i)materiais. Entender a relação entre ribeirinhos e território das águas nas suas múltiplas possibilidades instiga a compreensão sobre a realidade social de comunidades ribeirinhas como Vila Intel I, Vila Intel II e Magebras em muitas complexidades. Além das lideranças femininas e masculinas das comunidades, as falas de idosos, de jovens e de crianças revelam a importância dessas histórias, dando espaço para a manifestação geral.

As muitas aventuras, os desafios e as lutas fazem parte da paisagem social da região. O tempo do rio também se fará perceber nas dinâmicas sociais de seus encantamentos e na defesa do rio, da várzea e da terra-firme com as sutilezas e as forças dos ecossistemas e suas variadas formas de vida. As vidas ribeirinhas têm outro fio condutor para dizer o "lugar de fala" e a imposição do silêncio que também foi e é proposital. Tais vidas, assumidamente amazônidas, fazem jus à conformação geopolítica e socioeconômica que forjaram a região e as questões políticas e sociais que se sucederam. Não dá para falar da história da Amazônia sem colocar no centro as vidas indígenas e negras, caboclas e ribeirinhas em tempos tão injustos e de dominação.

$\mathrm{Na}$ percepção histórico-social dos povos das águas, a apreensão da realidade e das subjetividades em relação ao sistema de produção do local não tem ligações com noções de mercado, lucro e competitividade. Para tanto, são apreendidos no fluxo de informações e de produção conhecimentos avançados forjados na sociobiodiversidade da região que favoreçam a reprodução socioeconômica da vida ribeirinha. Aqui os relatos são fundamentalmente a força social, cultural e ancestral das palavras. $\mathrm{Na}$ residência comunitária são produzidos os quintais agroecológicos, exemplos de apreensão de conhecimentos intergeracionais adquiridos no território (i)material. Assim, destacam-se os saberes da terra, saberes das águas e saberes das florestas, cuja totalidade e diversidade possibilita uma visão alargada de educação essencial para apreensão dos movimentos de aprendizagem mais amplos e complexos que fazem parte das culturas singulares.

Foi nesse contexto de intercruzamento de saberes, de águas, de florestas, de memórias e de diversidade que se situa a importância de Paulo Freire para a ação do PRCR, tanto para a dialogicidade como processo formativo, quanto, e em especial, como valorização da palavra e sua nova pronúncia libertadora. A significação dessa palavra diante da opressão foi ganhando força durante a realização das oficinas nas comunidades ribeirinhas Vila Intel I, Vila Intel II e Magebras do Rio Parauaú. Esse rio, pertencente ao município de Breves, no arquipélago do Marajó, tem nas suas laterais a presença de muitas comunidades ribeirinhas que desenvolvem sistemas de informações próprios como prática social e cultural e suas diversas formas de falar, de gerar informação e transmiti-las como acontece com as comunidades Vila Intel I, Vila Intel II e Magebras, integradas por uma rede própria de informação que apresenta dificuldades em razão da distância entre as comunidades, da falta de combustível e de transporte rabeta (pequena embarcação) e/ou barco, somado ao fato da precarização da infraestrutura percebida nas comunidades. Essas condições socioeconômicas impedem uma maior e melhor circulação das informações e da qualidade do seu conteúdo, como, por exemplo, em períodos de vacina, em

Práxis Educativa, Ponta Grossa, v. 16, e2116641, p. 1-14, 2021 Disponível em: < https://www.revistas2.uepg.br/index.php/praxiseducativa> 
A força da palavra dos vulnerabilizados pela desigualdade social: Paulo Freire e comunidades ribeirinhas...

relação ao cadastro de famílias, à atualização das comunicações de aposentadoria, pensão e conhecimento das informações sobre direito coletivo.

Ocorridas em 2019, as oficinas foram baseadas nos temas "O que somos? E o que mais queremos ser?". Os ribeirinhos foram instigados com a finalidade de refletirem sobre a situação atual, revelando elementos conjunturais e estruturais. Dessa forma, podem compreender os cenários de exclusão social que configuram a região como a de maior vulnerabilidade social do Brasil e com os menores Índices de Desenvolvimento Humano (IDH) do Brasil (IBGE, 2010). Por essa razão, são áreas consideradas com maior vulnerabilidade social no país, junto a outros municípios marajoaras (Afuá, Anajás, Belém, Portel, Bagre, Chaves e Melgaço). Esse dado do IDH (IBGE, 2010) é a constatação do quanto a concentração de renda e a manutenção dos privilégios de uma elite econômica e política são responsáveis pela exclusão socioespacial na região. Durante o debate, os moradores das comunidades revelaram seus sentimentos, suas revoltas e sua desolação. A Figura 1, a seguir, revela uma das expressões manifestadas nas oficinas.

Figura 1 - Representação produzida por moradores da Vila Intel I, abril de 2019

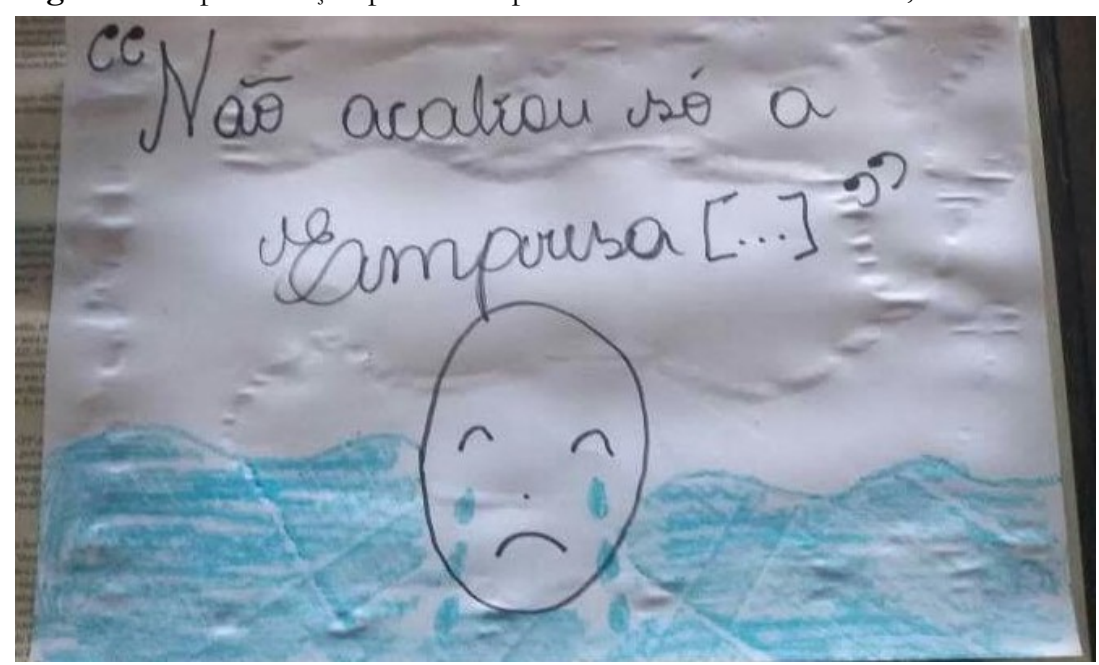

Fonte: Acervo do PRCR.

Em outro momento de análise sobre a atual conjuntura, um morador fez a seguinte reflexão:

Antes a vila era mais feliz, tinha mais gente, a gente comemorava, tinha festa. Não acabou só a empresa. [...]. A vila está acabada, esquecida.... a vila está destruida. Agora, pra sobreviver, alguns plantam, alguns pescam [...] e, com isso, vão levando a vida. [...] os moradores vivem da pesca do camarão e da produção de açaí e farinha. (Morador da Vila Intel I, abril de 2019).

As comunidades sentem-se, portanto, invisíveis. Há uma sensação de invisibilidade permanente que machuca: "[...] parece que a gente não existe pra lá [se referindo à Breves]" (Morador da Vila Intel I, abril de 2019). Esta constatação é muito comum: morar na beira do rio implica viver desprovido de alguns serviços e equipamentos de assistência. Essa situação se complexifica, pois $48 \%$ da população do município de Breves mora na zona rural, compreendida como área de águas e de florestas em uma região submissa ao alto grau de capital destrutivo e concentrador de renda proporcional ao drama social vivido por tantas famílias. Isso justificado pela prioridade dada às dinâmicas econômicas protagonizadas pelo Estado e pelos agentes financeiros que, por sua vez, rebatem e materializam-se, espacialmente, nos territórios das águas e das florestas com desmatamento, violência, doenças endêmicas, desemprego, defasagem escolar, insegurança alimentar, pontes ribeirinhas inviáveis para acessibilidade, transporte precário, dentre outros.

Práxis Educativa, Ponta Grossa, v. 16, e2116641, p. 1-14, 2021 Disponível em: <https://www.revistas2.uepg.br/index.php/praxiseducativa> 
Também durante as oficinas, foram utilizados cartazes para ambientar os participantes sobre o reconhecimento dos seus direitos, com imagens que ilustrassem os direitos básicos, como saúde, educação, moradia, dentre outros. Foram propostas atividades lúdicas que ajudaram nas dinâmicas interativas e proporcionaram um agudo senso crítico. Durante o desenvolvimento das atividades, a interação e a reflexão entre os moradores durante as oficinas mostraram a força social da palavra dos que são vulnerabilizados.

Quando Freire (1987) instiga a reflexão sobre a palavra, ele rompe com a ideia esquemática dela (foneticamente falando) e abre a possibilidade para o sentido humano da palavra. Quem pronuncia tem algo a dizer e está pleno do ato de ser reconhecido pelo que diz, na medida em que a dialogicidade e a escuta estão presentes para a efetiva e afetiva comunicação em direção a novas atitudes e reflexões: "A existência, porque humana, não pode ser muda, nem tampouco pode nutrirse e falsas palavras, mas de palavras verdadeiras, com que os homens transformam o mundo" (FREIRE, 1987, p. 79, grifo nosso). Ainda nessa direção, Freire estimula o entendimento de que a forma de ser e estar no mundo era sentido pela palavra: "Existir humanamente, é pronunciar o mundo, é modificálo. O mundo pronunciado, por sua vez, se volta problematizado aos sujeitos pronunciantes, a exigir deles novo pronunciar" (FREIRE, 1987, p. 79).

Ao pronunciar a palavra a partir de outras inquietações (Que papel estou exercendo? O que eu quero para o meu futuro?), o sentido amplo de educação vai sendo construído e gira em torno da humanização do mundo (FREIRE, 1996, 2000). A práxis transformadora que emerge das contradições sociais refaz processos e os imbrica em atos e possibilidades. São sujeitos políticos, produtores de conhecimentos ribeirinhos inscritos na territorialidade da sociobiodiversidade da Amazônia Marajoara, inerente aos povos que sabem produzir, cuidar de si e dos outros, porque sabem, desde sempre, que a vida e a natureza são similares. O fio condutor das ações nessa trama são as redes vivas de cuidado, de produção da vida, enfim, a produção da vida nas águas e nas florestas do Marajó.

\section{Enfrentamentos e insurgências: a palavra como centralidade para um outro horizonte possível}

As comunidades ribeirinhas mostram-se confiantes para refazer seus espaços como sujeitos de direito. A esperança e a dignidade, buscadas pelo sentido humano em Freire (1992, 2010), estão no centro dessas iniciativas. O sentimento presente nas falas dos sujeitos era de reconstrução e de perspectivas futuras. Nesse sentido, algumas iniciativas foram construídas: inclusão produtiva para ribeirinhos extrativistas, por meio da articulação entre agroecologia; valorização dos saberes tradicionais e qualificação social com envolvimento comunitário, utilizando tecnologias das águas e florestas para garantia da segurança alimentar; e integração com a preservação da natureza. Tais propostas estão sendo devidamente apresentadas e discutidas em parceria em uma perspectiva intersetorial entre as Faculdades de Serviço Social e Educação da UFPA - campus Marajó-Breves, o Instituto Chico Mendes de Conservação da Biodiversidade (ICMBio), as Cáritas Brasileira Região Norte, a Empresa de Assistência Técnica e Extensão Rural (EMATER/PA) e as Secretarias Municipais de Breves. Os campos de atuação da proposta são: produção coletiva; formação e informação para produção coletiva; qualificação social; e participação cidadã e comunitária. Todos eles são imbricados com os temas da cultura e da identidade, dos saberes da terra, da segurança alimentar, da inclusão produtiva, do cooperativismo, da economia solidária, do comércio justo, das tecnologias populares e da preservação da natureza. A partir dessas reflexões, o PRCR concebeu projetos com estratégias de trabalho baseados em atividades de produção coletiva, oficinas, rodas de conversa, produção de material envolvendo as dimensões produção, informação e formação. $O$ público-alvo são comunidades extrativistas ribeirinhas Vila Intel I, Vila Intel II e Magebras, com

Práxis Educativa, Ponta Grossa, v. 16, e2116641, p. 1-14, 2021 
A força da palavra dos vulnerabilizados pela desigualdade social: Paulo Freire e comunidades ribeirinhas...

destaque para aquelas situações em que o acesso, a dificuldade de transporte, a baixa prestação de serviços públicos são contínuos.

Aqui se coloca uma questão importante que é o sistema da economia local. Tal sistema é baseado no ecossistema de águas e de florestas em que o princípio da agroecologia de valorizar os saberes da terra e as experiências das comunidades são potencializados nos locais onde os sujeitos vivem e estabelecem, com a natureza, uma riquíssima relação de aprendizagem, sistematizada em códigos, símbolos e tecnologias próprias. Nesse sentido, pescadores, pequenos agricultores, extrativistas revivem e revisitam a sabedoria da ancestralidade ribeirinha, quilombola e indígena, as quais são referências em segurança alimentar e preservação ambiental, além de terem desenvolvido uma organização social e produtiva voltada ao mutirão, à partilha, à troca, ao trabalho comunitário e à solidariedade dos quintais, dos campos e das florestas.

Outra questão a ser evidenciada é a participação social que pressupõe cultura política e sociabilidade horizontal (FREIRE, 2000, 2010). Dessa forma, se quer qualidade deliberativa e capacidade distributiva, as quais incidem no controle social das políticas sociais em que a associação dos moradores cumpre um papel central. Os arranjos participativos vão sendo construídos à medida que se aumenta a capacidade das práticas de organização social das comunidades para romper com estruturas coloniais e com poder autoritário e, assim, construir redes de solidariedade e de cooperação via ações de base territorial, educativa e sociopolítica em uma interface com a Educação Popular em uma dinâmica centrada na cultura de direitos, radicalmente pautada na dignidade humana (FREIRE, 1987, 1992, 1996). O horizonte é a autonomia e a liberdade para criar e inovar processos em situações difíceis de desestruturação social; portanto, o cuidado entre as intracomunidades é relevante. A mística desse processo robustece os grupos e fortalece os vínculos que, também, são operadores da história e das memórias vivas dos que lutaram. Não se gesta cidadania sem memória e história (FREIRE, 2000).

O caráter do trabalho com comunidades exige valorização dessas memórias inscritas no território e na capacidade de mediação entre os saberes ribeirinhos e os conhecimentos acadêmicos, nos quais são potencializadas a diversidade e a interação de conhecimento e suas múltiplas possiblidades. Para Santos (2007), essa mediação que cruza e produz novas interações é denominada de ecologia de saberes. A produção de informação das comunidades e os métodos de sua partilha nas comunidades e entre elas, além de valorizar o saber existente, ativa o caráter de aprendizado tão rico e, também, potencializa o histórico de formação sociocultural dos povos da floresta. A ecologia de saberes, por conseguinte, é inspiradora para o fortalecimento do sistema de informação e para o incremento do cooperativismo intracomunidades. Soma-se a ela o caráter emancipatório e histórico do ser que aprende quando se relaciona (FREIRE, 2000).

Ao mesmo tempo em que são invisibilizados por uma trama privatista e de mercado, esses grupos socialmente diferenciados têm seus saberes negados e inferiorizados. Sobre isso, importa destacar que a matriz da racionalidade técnica, baseada em modelos clássicos de decisão (GIANELLA, 2008), portanto hierárquicos e lineares, inspira os programas e os projetos do Estado e de grandes empreendimentos, evidenciando a supremacia do conhecimento científico considerado "legítimo e racional" (GIANELLA, 2008, p. 13). Ainda que essa matriz seja justificada pela ideologia do desenvolvimento, as prerrogativas de eficácia social, coerência institucional, consistência técnica, previsibilidade e ordenação máxima foram incapazes de evitar destruição ambiental, conflitos territoriais, instabilidades políticas que aprofundaram as desigualdades sociais na região, resultado da complexidade de tramas sociais globo-local e da conformação histórica, política e econômica inscritas no território, não podendo ser desconsideradas por se tratar de processos da conformação espaço-temporal do sistema-mundo capitalista (BRANDÃO, 2012). Desse modo, a fase contemporânea do capital reatualiza as formas de destruição socioambiental

Práxis Educativa, Ponta Grossa, v. 16, e2116641, p. 1-14, 2021

Disponível em: < https://www.revistas2.uepg.br/index.php/praxiseducativa> 
da sociedade que, por seu turno, atingem diretamente os grupos socialmente diferenciados, negando o território; e as territorialidades são espaços das palavras como matrizes, essenciais para assegurar a partilha e o aprendizado coletivo (FREIRE, 1992). Em termos da participação social, a palavra nas comunidades ribeirinhas é um instrumento para conquista de direitos socioterritoriais, considerando informação e formação como eixos de sustentação do compartilhamento de ideias, notícias e aprendizagens com vistas à cidadania.

Nesse patamar, para as comunidades ribeirinhas, as reuniões de trabalho centrados na Educação Popular são significativas. Com temáticas informativas e formativas sempre grupais e conectadas com as singularidades da vida ribeirinha, há grande possibilidade de ampliar a cultura rica de saberes e de experiências, forjada no território, mostrando a proximidade dos temas mais próximos e seus impactos aos espaços dos rios, das florestas e das várzeas, onde a vida se reproduz na Mesorregião do Marajó. Há demandas e especificidades nesses processos informativos e formativos vinculados; no entanto, alguns itinerários possíveis são imprescindíveis na perspectiva do cuidado integral: água e vida; preservação do meio ambiente; e segurança alimentar.

Ademais, esses temas serão trabalhados nas escolas das comunidades ribeirinhas em parceria com os profissionais da educação. Metodologias colaborativas e participativas são essenciais para que, de fato, a interculturalidade seja experienciada em sua dimensão efetiva e afetiva como aproximadora de mundos de aprendizagens (científico e tradicional), respeitando as especificidades sociodemográficas e culturais deste território, que possui a maior bacia fluviohidrográfica do mundo, e buscando a inclusão permanente do ribeirinho como ator nos processos grupais e em equipes de cuidado integral com sua história, sua memória, seus códigos e seus saberes. Esse destaque é feito em decorrência da ausência de espaços e de canais de diálogo e escuta sensível junto aos problemas e às demandas dos ribeirinhos. O protagonismo do ribeirinho é, dessa maneira, o maior e mais importante desafio como direito social.

Nesse sentido, é mister continuar a catalogar, a sistematizar e a operar múltiplos conhecimentos ambientados nas comunidades ribeirinhas às margens do Rio Parauaú, no território das águas e das florestas marajoaras, tendo os saberes das populações da beira do rio como principal foco e a partir delas desenvolver centralidades e ancestralidades. O ambiente e o foco, atravessados pela rede de cultura, de identidade e de ciência, contornam o movimento histórico das relações concretas dessas populações com o ecossistema, na perspectiva de conhecerem como preservam, cuidam dos seus espaços de vida e lutam por cidadania.

\section{Considerações finais}

O desafio, no século XXI, em que há o avanço do sistema capitalista, é manter a riqueza da cultura e da forma de viver e de produzir e dela garantir a vida de grupos sociais na Amazônia Marajoara que querem continuar sendo o que são: povos da floresta e das águas, mas com direito à vida e à preservação da natureza. Para tanto, é necessário adotar uma postura de reflexividade na compreensão do mundo em sua multidimensionalidade. E as questões-instigantes continuam: Como formar, informar e incentivar participação em cenários de profunda desigualdade? Como ampliar a organização social de comunidades diante de intensos processos de desestruturação social? Não há respostas conclusivas, mas algumas pistas são sinalizadoras: elevação da autoestima das comunidades ribeirinhas, valorização do coletivo como empoderamento e produção de uma narrativa que desnaturalize a pobreza.

Esses aspectos asseguram o ambiente de contradiscurso diante de uma visão hegemônica "de que não tem mais jeito". Outro aspecto importante para a metodologia é a entrada no campo de atuação e compreender a espacialização das comunidades no "labirinto" de rios. Perceber o

Práxis Educativa, Ponta Grossa, v. 16, e2116641, p. 1-14, 2021

Disponível em: <https://www.revistas2.uepg.br/index.php/praxiseducativa> 
A força da palavra dos vulnerabilizados pela desigualdade social: Paulo Freire e comunidades ribeirinhas...

contexto histórico e a reprodução social das comunidades ribeirinhas são vitais e recomendadas para aceitação e acolhida no campo.

De um modo geral, a proposta de tecer teias de participação social visa a reconhecer, potencializar e articular ações ribeirinhas com foco na reapropriação social da natureza no território das águas e das florestas como diversidade sociocultural da Amazônia e direito humano constitucional. A cultura do ribeirinho e a palavra são intergeracionais, pois, desde pequenas, as crianças são ensinadas a nadar, a pescar, a caçar, a plantar, a extrair açaí etc., o que implica absorção dos costumes pela oralidade e histórias contadas nas comunidades, e, assim, continuam mantendo essa ligação com a natureza. No entanto, o atual quadro aponta a permanente exploração dos recursos naturais da Amazônia em uma dimensão ainda colonialista. Percebe-se que as violações de direitos, a injustiça ambiental e a superioridade correspondem à cultura da opressão pela imposição dos poderes políticos e econômicos, os quais são responsáveis pelos conflitos sociais e pelo aprofundamento da extrema pobreza na região com menores IDH no Brasil.

A ideia central para garantir a reprodução social da vida ribeirinha é a defesa e a efetivação de direitos, a ampliação da participação social e o permanente mutirão de informações de caráter aberto, coletivo e centrado na palavra gestada e organizada como núcleo articulador suficientemente representativo das comunidades envolvidas para as ações de cooperativismo, geração de renda, saberes e direitos. Soma-se a isso o fato de resistir à visão racista de preconceituosamente subjugar outros tipos de culturas, saberes e modos de vida, cunhandoos como "atrasados" para justificar o avanço das atrocidades e da destruição provocado pela expansão do sistema capitalista e, assim, naturalizar a exclusão social na Amazônia Marajoara.

A palavra como centralidade é essencial para uma cultura de direitos e um futuro portador de esperança e de dignidade. São necessários esforços e aprendizados para a cocriação, a produção compartilhada de conhecimento e o diagnóstico para o enfrentamento político e coletivo dos problemas nas dimensões micro do território e macro da sociedade em suas determinações, em busca de soluções coletivas com a rede de atores e de entidades. Os temas da negação das comunidades ribeirinhas, do processo saúde-doença e da geração de renda são essenciais.

O foco no protagonismo ribeirinho, como sujeito histórico na integralidade das ações, é essencial para a multiplicidade de outras oportunidades que se abrirão no território das águas. A partir dessas reflexões, o incremento da Educação Popular como projeto político é estratégico, concebido nas metodologias participativas desenvolvidas em oficinas, rodas de conversa, produção de material, envolvendo as dimensões humana, cidadã e ética. Dessa forma, as comunidades ribeirinhas vislumbram construir espaços e cenários que façam alusão ao fato de a cultura de direitos problematizar permanentemente a realidade como produção social, com a visão de denúncia e anúncio, incrementando o nível de engajamento e participação dos sujeitos políticos dos territórios das águas e das florestas. Aproximar essas orientações em uma ação metodológica intersetorial, interdisciplinar, integral, macrossocial, híbrida e relacional é o maior desafio das redes de comunidades ribeirinhas, ao considerarem as redes como espaços de saberes, experiências e ações políticas, de modo a alavancarem planos intersetoriais de cuidado e de emancipação social na perspectiva freireana.

\section{Referências}

BÔAS, L. M. da S. V.; OLIVEIRA, D. C. de. A Saúde nas comunidades ribeirinhas da Região Norte brasileira: revisão sistemática da literatura. In: CONGRESSO IBERO-AMERICANO EM INVESTIGAÇÃO QUALITATIVA (CIAIQ) - Investigação Qualitativa em Saúde, v. 2, 2016. Porto. Anais [...]. Porto: CIAIQ, 2016. p. 1386-1395.

Práxis Educativa, Ponta Grossa, v. 16, e2116641, p. 1-14, 2021 Disponível em: < https://www.revistas2.uepg.br/index.php/praxiseducativa> 
BRANDÃO, C. A. Território e desenvolvimento: as múltiplas escalas entre o local e o global. 2. ed. Campinas: Editora da Unicamp, 2012.

CASTRO, E. Políticas de estado e atores sociais na Amazônia contemporânea. In: BOLLE, W.; CASTRO, E.; VEJMELKA, M. (org.). Amazônia: região universal e teatro do mundo. São Paulo: Globo, 2010. p. 105-122.

CASTRO, E. M. R. Expansão da fronteira, megaprojetos de infraestrutura e integração sulamericana. Caderno do CRH, Salvador, v. 25, n. 64, p. 45-61, jan./abr. 2012. DOI: https://doi.org/10.1590/s0103-49792012000100004

FREIRE, P. Pedagogia do Oprimido. 22. ed. Rio de Janeiro: Paz e Terra, 1987.

FREIRE, P. Pedagogia da Esperança: um reencontro com a Pedagogia do Oprimido. Rio de Janeiro: Paz e Terra, 1992.

FREIRE, P. Pedagogia da Autonomia: saberes necessários à prática educativa. São Paulo: Paz e Terra, 1996.

FREIRE, P. Pedagogia da Indignação: cartas pedagógicas e outros escritos. São Paulo: Editora UNESP, 2000.

FREIRE, P. Educação e mudança. Rio de Janeiro: Paz e Terra, 2010.

G1-PARÁ. Em Breves, no PA, 1 a cada 4 moradores foi infectado por Covid-19, aponta estudo. Jornal Liberal, Belém, 25 maio 2020. Disponível em: https://g1.globo.com/pa/para/noticia/2020/05/25/em-breves-no-pa-1-a-cada-4-moradoresforam-infestados-por-covid-19-aponta-estudo.ghtml. Acesso em: 20 jun. 2020.

GIANNELA, V. Base teórica e papel das metodologias não convencionais para formação em gestão social. In: CANÇADO, A. C. et al. (org.). Os desafios da formação em Gestão Social. Palmas: Provisão, 2008. p. 11-17

GONÇALVES, M. E. S.; BOMFIM, L. S. V. Pensamento/ação freiriano: pistas para uma epistemologia descolonial que cimente uma Ecologia Humana contra-hegemônica. Práxis Educativa, Ponta Grossa, v. 16, e2116594, p. 1-15, 2021. DOI: https://doi.org/10.5212/praxeduc.v.16.16594.021

GUDYNAS, E. Extractivismos en America der Sur: conceptos y sus efectos derrame. In: ZHOURI, A.; BOLADOS, P.; CASTRO, E. (ed.). Mineração na América do Sul: neoextrativismo e lutas territoriais. São Paulo: Editora Annablume, 2016. p. 23-43.

IBGE. Instituto Brasileiro de Geografia e Estatística. Extrema Pobreza atinge 13, 5 milhões de pessoas e chega ao maior nível em 7 anos. Agência IBGE, 6 nov. 2019. Disponível em: https://agenciadenoticias.ibge.gov.br/. Acesso em: 20 ago. 2020.

LOUREIRO, J. J. P. Cultura Amazônica: uma poética do imaginário. 4. ed. Belém: Cultura Brasil, 2015.

PORTO-GONÇALVES, C. W. Amazônia enquanto acumulação desigual de tempos: Uma contribuição para a ecologia política da região. Revista Crítica de Ciências Sociais, n. 107, p. 6390, abr. 2015. DOI: https://doi.org/10.4000/rccs.6018 
A força da palavra dos vulnerabilizados pela desigualdade social: Paulo Freire e comunidades ribeirinhas...

QUIJANO, A. Colonialidade do poder e classificação social. In: SANTOS, B. S.; MENESES, M. P. (org.). Epistemologias do Sul. São Paulo: Cortez, 2010. p. 84-130.

ROMÃO, J. E.; GADOTTI, M. Paulo Freire e Amílcar Cabral: a descolonização das mentes. São Paulo: Editora e Livraria Instituto Paulo Freire, 2012.

SANTOS, B. S. Renovar a teoria crítica e reinventar a emancipação social. São Paulo: Boitempo, 2007.

SILVA, F. C.; AMIM, M. M.; NUNES, S. F. (org.). Sustentabilidade dos Municípios da Amazônia. Belém: Editora do NAEA/UFPA, 2015. (Coleção Formação Regional da Amazônia).

Recebido em 11/08/2020

Versão corrigida recebida em 17/04/2021

Aceito em 18/04/2021

Publicado online em 03/05/2021 